\title{
The Journey Towards Lung Protective Respiratory Support in Preterm Neonates
}

\author{
Thomas M. Berger Matteo Fontana Martin Stocker \\ Neonatal and Pediatric Intensive Care Unit, Children's Hospital of Lucerne, Lucerne, Switzerland
}

\begin{abstract}
Key Words
Antenatal corticosteroids - Atelectrauma .

Bronchopulmonary dysplasia - Continuous positive airway pressure - Conventional mechanical ventilation . High-frequency oscillatory ventilation · Lung-protective strategies - Noninvasive respiratory support - Oxygen toxicity $\cdot$ Surfactant $\cdot$ Volutrauma
\end{abstract}

\begin{abstract}
The aim of this conceptual review is to provide the reader with a broad perspective on progress made in respiratory support of preterm infants over the past five decades. Landmark discoveries are described in their historical context and underlying theories of lung protection are discussed. The review finishes by integrating different approaches and perspectives into a state-of-the-art concept for lung-protective ventilation in this fragile patient population. Improvements in neonatal respiratory support in the 1970s and 1980s have contributed to dramatic improvements of mortality and morbidity rates among neonates with respiratory failure. Continuous positive airway pressure, antenatal corticosteroids and surfactant replacement therapy revolutionized the care of preterm infants. With the recognition that atelectrauma, volutrauma and oxygen toxicity are the main factors contributing to ventilator-induced lung injury, lung-protective strategies, including noninvasive respiratory support, tidal volume targeting during conventional mechanical ventilation and high frequency ventilation were developed in
\end{abstract}

the 1990s. Given the fact that progress made in the last decade has only resulted in minor improvements in mortality and morbidity rates of neonates with respiratory failure, it seems unlikely that further refinements of current technologies will produce giant leaps forward in high-resource countries. It appears that entirely new approaches would be required. In contrast, knowledge and technology transfer of basic respiratory support strategies (e.g. use of oxygen, simple systems to provide continuous positive airway pressure), could have an enormous impact on the prognosis of neonates with respiratory failure in low-resource countries.

() 2013 S. Karger AG, Basel

\section{Introduction}

Progress made in the field of perinatology over the past five decades has led to dramatically improved mortality and morbidity rates among sick newborn infants. While advances in prenatal care and regionalization of perinatal care have played an important role, the most important changes that have contributed to this success have occurred in the field of neonatal respiratory care.

This review will describe the journey towards lung protective respiratory support in neonates. Progress made over the past five decades has been outstanding. The vast majority of infants with respiratory failure who were doomed in the 1960 s can now be expected to survive.

\section{KARGER}

E-Mail karger@karger.com

www.karger.com/neo
(C) 2013 S. Karger AG, Basel

1661-7800/13/1044-0265\$38.00/0
Prof. Thomas M. Berger, MD

Neonatal and Paediatric Intensive Care Unit

Children's Hospital of Lucerne

CH-6000 Lucerne (Switzerland)

E-Mail thomas.berger@luks.ch 


\section{Before 1960: Missteps, Falls and a First Important Milestone}

Sixty years ago, for newborn infants with respiratory distress of various etiologies, the provision of supplemental oxygen was the sole therapeutic option and its impact could only be assessed clinically. When it was recognized that exposure to high concentrations of oxygen could cause retrolental fibroplasia (now known as retinopathy of prematurity or ROP) and result in blindness [1], a strategy of restricted oxygen use was adopted but may have resulted in increased mortality rates from respiratory failure [2].

In 1959, Avery and Mead [3] published their seminal observation of an increased surface tension in lung liquid samples from babies who had died from hyaline membrane disease (HMD) and suggested that preterm infants lacked a surface-active agent (i.e. surfactant). In those days, preterm infants who developed HMD either died within the first 3 days of life or recovered completely after 7-10 days [4]. It would take another 20 years until the first report of surfactant replacement therapy would be published [5]; in the meantime, a series of discoveries started to change the hitherto dire prognosis of neonates with respiratory failure.

\section{The 1960s: Marching into the Bronchopulmonary Dysplasia Epidemic}

1963 was a pivotal year for the new field of neonatology, when the son of President John F. Kennedy, Patrick Bouvier Kennedy, died from complications of HMD on his third day of life after having been born at 34 weeks' gestation with a birth weight of $2,100 \mathrm{~g}$. At that time, the first experiences with invasive mechanical ventilatory support of neonates outside of the delivery room and beyond the immediate postpartum period had already been published. The death of the son of the American President accelerated the development and deployment of infant ventilators, micro-blood gas analysis and umbilical artery catheterization, and led to the development of intensive care for newborns in the 1960s on both sides of the Atlantic.

In those early years of neonatal mechanical ventilation, air leak syndromes and its complications were very common and felt to be related to high airway pressures (i.e. barotrauma). Nevertheless, the addition of mechanical ventilation to the neonatal intensive care unit (NICU) armamentarium improved survival rates of neonates with respiratory failure. However, in contrast to the natu- ral history of HMD observed 10 years earlier [4], complete recovery was no longer the only outcome in survivors as many went on to develop a new form of chronic lung disease. Based on its histological features, the term bronchopulmonary dysplasia (BPD) was introduced by Northway et al. [6] who published their observations in 1967. Infants who required high concentrations of supplemental oxygen and high peak inflation pressures were at greatest risk to develop BPD [6].

\section{The 1970s: Giant Leaps Forward}

Two discoveries made in the 1970s, once adopted, had a profound impact on the prognosis of preterm infants. The first one, reported in 1971, was made by Gregory et al. [7] when they were able to demonstrate that continuous positive airway pressure (CPAP) delivered via endotracheal tube or by a sealed head chamber (the 'Gregory Box') in preterm infants with HMD dramatically reduced the mortality rate of these infants from an expected rate of $75-20 \%$.

The second discovery was based on the observation that fetal lung maturation could be accelerated by the administration of antenatal corticosteroids (ANC) [8]. In 1972, Liggins and Howie [9] published the results of a randomized controlled trial of ANC, which showed that the risk of HMD and death were both almost halved in ANC exposed preterm infants. These findings were later confirmed by several additional studies and meta-analyses [10].

Perhaps not unexpectedly, with sicker infants surviving, the incidence of BPD was not lowered. In fact, BPD became a veritable scourge of neonatal intensive care. Some affected infants could never be weaned from mechanical ventilation, and, upon graduation from the NICU, were transferred to pediatric intensive care units only to succumb after months to lower respiratory tract infections or chronic right heart failure.

\section{The 1980s: Another Huge Jump}

In the 1980s, following the initial observation of a beneficial effect of exogenous surfactant on pulmonary gas exchange in a small case series by Fujiwara et al. [5], several large randomized controlled surfactant trials explored the efficacy of various treatment (prevention versus rescue) and dosing regimens [11]. By the end of the decade, the use of surfactant to prevent or treat HMD was well established and revolutionized the care of these in- 
Table 1. Changes in survival and BPD rates

\begin{tabular}{|c|c|c|c|c|}
\hline & \multicolumn{2}{|l|}{ Survival rate } & \multicolumn{2}{|c|}{$\begin{array}{l}\text { BPD rate in survivors } \\
\text { survivors }\end{array}$} \\
\hline & $1962-1965$ & 1989 & $1962-1965$ & 1989 \\
\hline$<1,000 \mathrm{~g}$ & $\begin{array}{l}0 \% \\
(0 / 3)\end{array}$ & $\begin{array}{l}86 \% \\
(30 / 35)\end{array}$ & $\begin{array}{l}\text { not } \\
\text { applicable }\end{array}$ & $\begin{array}{l}73 \% \\
(22 / 30)\end{array}$ \\
\hline $1,001-1,500 \mathrm{~g}$ & $\begin{array}{l}29 \% \\
(2 / 7)\end{array}$ & $\begin{array}{l}94 \% \\
(34 / 36)\end{array}$ & $\begin{array}{l}50 \% \\
(1 / 2)\end{array}$ & $\begin{array}{l}24 \% \\
(8 / 34)\end{array}$ \\
\hline$>1,500 \mathrm{~g}$ & $\begin{array}{l}50 \% \\
(11 / 22)\end{array}$ & $\begin{array}{l}98 \% \\
(47 / 48)\end{array}$ & $\begin{array}{l}27 \% \\
(3 / 11)\end{array}$ & $\begin{array}{l}6 \% \\
(3 / 47)\end{array}$ \\
\hline $\begin{array}{l}\text { All ventilated } \\
\text { infants with RDS }\end{array}$ & $\begin{array}{l}41 \% \\
(13 / 32)\end{array}$ & $\begin{array}{l}93 \% \\
(111 / 119)\end{array}$ & $\begin{array}{l}31 \% \\
(4 / 13)\end{array}$ & $\begin{array}{l}30 \% \\
(33 / 111)\end{array}$ \\
\hline
\end{tabular}

Improved outcomes of mechanically ventilated infants with RDS at Stanford University Medical Center between 1962-1965 and 1989 [13].

Inclusion criteria: infants ventilated with positive pressure ventilation for HMD for more than $24 \mathrm{~h}$.

Definition of BPD: requirement for supplemental oxygen at 28 days of life.

fants. Some years later, when studies clarified the important functions of surfactant-associated proteins, most NICUs switched from protein-free artificial surfactant preparations to the more efficient animal-derived natural surfactants, which contained the hydrophobic surfactant associated proteins SP-B and SP-C [12].

\section{Changing Appearance of BPD}

By the end of the 1980s, significant advances had been made in the treatment of premature infants with HMD. Comparing mortality and BPD rates at the Stanford University Medical Center between 1963-1965 and 1989, Northway [13] was able to demonstrate the dramatic impact the implementation of new techniques in neonatal respiratory care had made over the previous 25 years. With improved survival of more immature infants, the overall incidence of BPD had not changed, but the disease burden had clearly shifted to surviving extremely low birth weight infants (table 1) [13].

\section{The 1990s: Further Steps in the Right Direction}

\section{Progress in Conventional Mechanical Ventilation}

Parallel to the discoveries of corticosteroid-induced acceleration of fetal lung maturation, CPAP and surfac- tant replacement therapy, mechanical ventilators were continuously adapted to meet the special needs of neonatal patients. For almost three decades, continuous-flow, time-cycled, pressure-limited devices had been the standard for invasive neonatal ventilatory support. In the 1990s, with the incorporation of microprocessor technology and lightweight flow and pressure transducers, mechanical ventilators became increasingly sophisticated. Clinicians could now choose from a large menu of ventilation modes and modalities [14].

Using flow or pressure sensors and microprocessor technology with short response times, new modes of ventilation were able to synchronize the delivery of mechanical inflations with the patient's own spontaneous breathing effort. Although the use of patient-triggered modes of mechanical ventilation improved patient-ventilator asynchrony and was associated with a shorter duration of ventilation, other advantages in important clinical outcomes could not be demonstrated [15].

\section{Volume-Targeted Ventilation}

By the end of the decade, following an encouraging preliminary report by Amato et al. [16], a large randomized controlled trial confirmed that a lung-protective strategy including positive end-expiratory pressure (PEEP) optimization and tidal volume limitation (6 vs. 12 $\mathrm{ml} / \mathrm{kg}$ ) could decrease mortality rates in adult ARDS patients [17]. Although no comparable studies have been performed in preterm neonates, several clinical trials have shown that volume-targeted ventilation (VTV) delivers more stable tidal volumes than pressure-limited ventilation. In addition, VTV has the advantage of automatically reducing inflation pressures when lung compliance improves with resolution of the underlying pulmonary condition, a process that has been referred to as auto-weaning. A recent meta-analysis of nine randomized trials concluded that VTV significantly reduced the combined rates of death or BPD (RR 0.73, 95\% CI 0.57-0.93) with a number needed to treat of 8 , whereas there was only a borderline reduction in BPD alone (RR 0.73, 95\% CI 0.53-1) [18]. In addition, there were significant reductions in the incidence of pneumothorax, the duration of mechanical ventilation, the incidence of hypocarbia, and the combined outcome of severe intraventricular hemorrhage or periventricular leukomalacia [18]. While these results are encouraging, some caution seems justified as the analysis is based on relatively small trials using a variety of ventilators with different modes of VTV $[18,19]$. Currently, no data on long-term neurodevelopmental and respiratory outcomes are available [18]. 

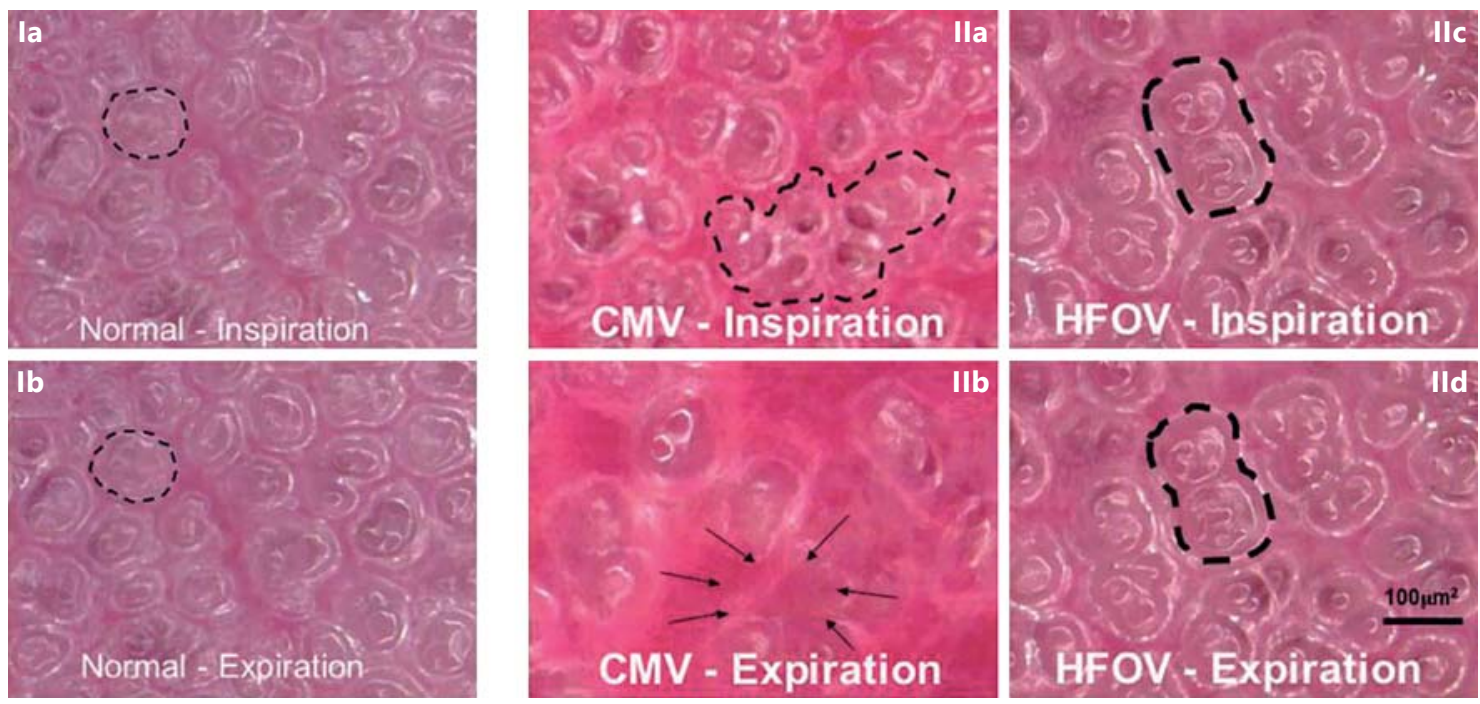

Fig. 1. In vivo photomicrographs of alveolar dynamic behaviour. In normal lungs, alveolar diameters change minimally during tidal ventilation (Ia, b), in injured lungs, there is alveolar collapse at end-expiration during CMV (IIa, b), whereas HFOV is able to maintain alveolar stability (IIc, d). Reproduced with permission from Carney et al. [21].

\section{Introduction of High-Frequency Ventilation into} Clinical Practice

Once it had been accepted that atelectrauma, volutrauma and oxygen toxicity were important mechanisms propagating ventilator-induced lung injury, research focused on modes of ventilation that would help stabilize functional residual capacity to prevent collapse of lung units, limit tidal volume to avoid overdistension and minimize oxidative stress. Compared with conventional mechanical ventilation (CMV), high-frequency ventilation appeared more promising to address these issues separately, and animal studies clearly indicated its superiority [20]. Several devices were developed for clinical use, including the most commonly used high-frequency oscillatory ventilators (HFOV), and the less popular high-frequency flow interrupters and high-frequency jet ventilators.

In an important animal study, Carney et al. [21] have shown by in vivo microscopy that in normal lungs alveolar diameters change minimally during tidal ventilation, regardless of the size of the tidal volume; in contrast, in injured lungs there is alveolar instability with total collapse at end-expiration (fig. 1, Ia, b, IIa, b). Shear stressinduced injury is most pronounced in alveoli that collapse and reopen with each breath. Since some alveoli are not recruited during inflation, the tidal volume is redistributed to the open lung units; even physiological tidal volumes may then cause overdistension of these units (i.e. volutrauma). In their experiments, the authors demon- strated that HFOV was superior to CMV in improving alveolar stability (fig. 1, IIa-d) [21].

In 1989, the HIFI Study Group published the results of the first randomized clinical trial comparing efficacy and safety of HFOV and CMV in the treatment of respiratory failure in preterm infants [22]. HFOV did not reduce mortality (18 vs. $17 \%$ with CMV; $\mathrm{p}=0.73$ ) and had no impact on the incidence of BPD ( 40 vs. $41 \%$ with CMV, $\mathrm{p}=0.79$ ).

Meta-analyses of a series of additional trials conducted over the next 20 years showed no evidence of a reduction in mortality at 28 days and only a small reduction in the rate of BPD with the use of HFOV compared to CMV, regardless of whether HFOV was used as a rescue intervention after failed conventional ventilation in near term or term infants (BPD defined as supplemental oxygen at 28-30 days or at discharge home: RR 2.26, 95\% CI 0.865.90) [23], or electively for the prevention of moderate or severe BPD in preterm infants (RR 0.95, 95\% CI $0.88-$ 1.03) $[24,25]$. HFOV can be a valuable alternative to conventional mechanical ventilation. Understanding its mechanisms of action and an appreciation of its inherent risks are prerequisites for its successful use [26].

\section{On the Way, BPD Continued to Evolve}

Although progress in neonatal respiratory care had continued during the 1990s with the introduction of technologically sophisticated ventilators, its impact on outcome was less impressive compared with the discoveries 
Fig. 2. The changing appearance of $B P D$. a Classical BPD, as described by Northway in 1967, is now rarely seen. b Instead, infants who are oxygen dependent at 36 weeks often show bilateral diffuse, fine infiltrates.
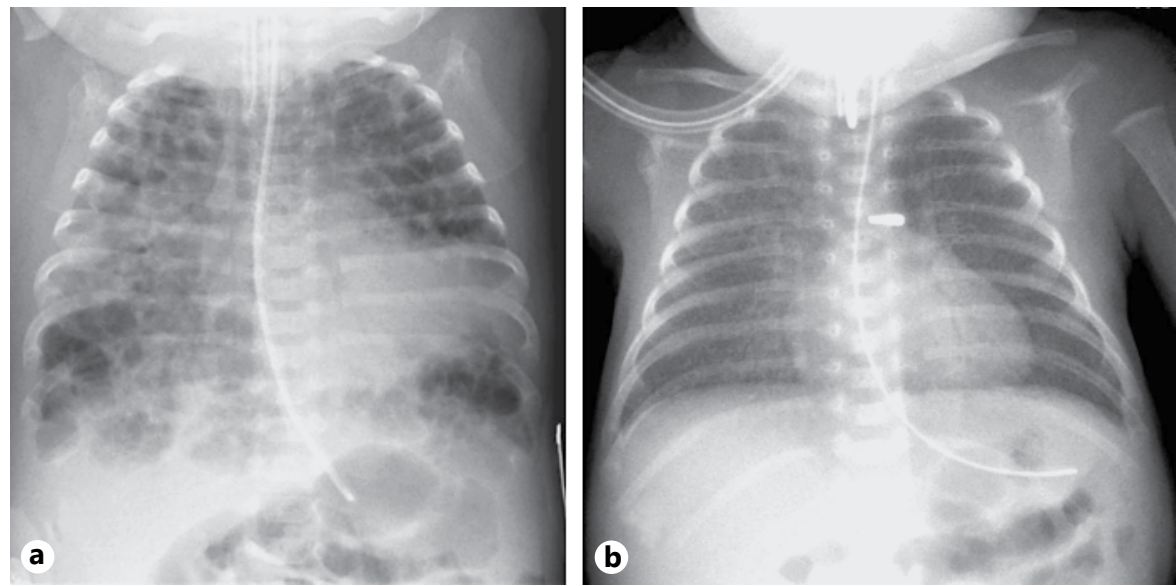

made in the previous decades. Nevertheless, by the end of the second millennium, gentler ventilation techniques, ANC and surfactant replacement therapy had minimized severe lung injury in larger and more mature infants and BPD had become infrequent in preterm infants with a birth weight of more than $1,200 \mathrm{~g}$ or with a gestational age exceeding 30 weeks. The disease was now mostly seen in extremely low birth weight infants and its clinical and radiological appearance had changed significantly (fig. 2) [27].

Apart from alveolar septal fibrosis, which was less pronounced in surfactant-treated infants, the pathology of the disease in infants born at less than 28 weeks of gestation was now characterized by a partial arrest in acinar development [28]. To account for these changes, Jobe [29] coined the term 'new BPD'.

\section{The 2000s: Old Roads Revisited}

\section{Is a Noninvasive Approach the Way to Go?}

Already in 1987, Avery et al. [30] had published a seminal observational study among eight NICUs on centerspecific rates of oxygen dependency at 28 days of life. They had noted that the center with the least invasive approach had by far the lowest rate of BPD. This center, Columbia Presbyterian Medical Center, New York, had adopted a policy of nasal CPAP as the primary mode of respiratory support in preterm infants with respiratory distress, whereas most of the other centers preferred intubation and mechanical ventilation.

During the first decade of the new century, three large international multi-centre trials were conducted to define the role of early CPAP [31-33]. Despite slightly different entry criteria, indications for intubation and surfactant administration, the results of these trials were remarkably similar. No trial demonstrated a significant difference in the primary endpoint (i.e. BPD or death). However, a recent Cochrane review concluded that initial stabilization with CPAP and surfactant rescue therapy in infants failing CPAP is associated with less risk of the combined outcome of BPD or death (RR 1.12, 95\% CI 1.02-1.24) compared to elective intubation and prophylactic surfactant administration [34]. It is noteworthy that the failure rate of early CPAP is quite high (46-83\%) [31-33], and delayed intubation, appears to be associated with an increased risk of air leaks [33].

\section{Redefining the Role of Adjuvant Therapies}

Surfactant Administration

In 1994, Verder et al. [35] published their experience with a new strategy that involved intubation, surfactant administration and rapid extubation to CPAP (later named the INSURE procedure). In this small-scale study, surfactant treatment significantly reduced the need for subsequent mechanical ventilation $(43 \%$ in surfactanttreated infants, as compared with $85 \%$ in controls, $\mathrm{p}=$ $0.003)$. Several additional trials using INSURE followed [31, 36-39]. While some of these studies demonstrated a significantly decreased need for mechanical ventilation after INSURE $[37,38]$, this apparent benefit did not translate into decreased rates of mortality or BPD [40]. Finally, when INSURE is used, prophylactic surfactant is not superior to CPAP and early selective surfactant with regards to the requirement for mechanical ventilation in the first 5 days of life [41].

In the era of noninvasive respiratory support, neonatologists became interested in new techniques of minimally invasive surfactant therapy (MIST). Small feasibil- 
ity studies using pharyngeal bolus instillation [42], surfactant administration through a laryngeal mask airway [43], or through a catheter inserted through the vocal cords $[44,45]$, demonstrated a beneficial effect on oxygenation. Recently, the results of the first multicenter open-label, randomized controlled trial comparing MIST with conventional therapy (i.e. CPAP, rescue intubation and surfactant treatment if needed) in 220 preterm infants with a gestational age between $260 / 7$ and $286 / 7$ weeks have been published [46]. Although the study showed that the risk for need of any mechanical ventilation was significantly lower after MIST (33 and $73 \%$ in the intervention and conventional therapy groups, respectively; $\mathrm{p}<0.0001$ ), the risk of death or BPD at 36 weeks' postmenstrual age did not differ (14 and 15\%, respectively) [46]. Another recently published single-center study compared INSURE to a modified MIST procedure (the so-called Take Care procedure) which entailed early administration of surfactant via a thin catheter during spontaneous breathing without disruption of CPAP support. In addition to a significantly reduced requirement for mechanical ventilation in the first $72 \mathrm{~h}$ of life (30 vs. $45 \%$, $\mathrm{p}=0.02$ ), the rate of moderate-to-severe BPD in survivors was significantly lower in the Take Care group (10.3 vs. $20.2 \%, \mathrm{p}=0.009$ ) [47].

\section{Inhaled Nitric Oxide}

When nitric oxide was identified as the previously propagated endothelium-derived relaxing factor, inhaled nitric oxide (iNO) was felt to be a potentially valuable new therapeutic modality to selectively influence pulmonary vascular tone in sick neonates, and its precise role was subsequently investigated in numerous randomized controlled trails. Initially, infants born at or near term with PPHN were studied. Because infants with PPHN have a high risk of dying, extracorporeal membrane oxygenation was introduced in the 1990s as rescue intervention if conventional therapy failed. A meta-analysis published in 2006 included 14 randomized controlled trials and demonstrated that iNO-treated near-term and term infants were significantly less likely to require extracorporeal membrane oxygenation [48].

When it was shown in preclinical trials that iNO was able to modulate key steps in the pathogenesis of BPD (i.e. decrease lung inflammation and neutrophil infiltration, reverse the inhibition of vascular endothelial growth factor, stimulate angiogenesis and alveolarization) [49], iNO was studied in preterm infants at high risk of developing BPD [50]. Despite these promises, the results of two recently published meta-analyses of studies of iNO in pre- term infants were disillusioning: in preterm infants, iNO is neither effective as a rescue therapy for severe respiratory failure, nor in decreasing the incidence of BPD [50, 51].

Caffeine

Methylxanthines such as theophylline and caffeine are frequently used to reduce the frequency of apnea of prematurity and the need for mechanical ventilation. In 2006, the results of the CAP (caffeine for apnea of prematurity) trial showed that caffeine treated infants could be weaned from positive pressure support 1 week earlier (at median postmenstrual ages of 31 and 32 weeks, respectively) and had a lower incidence of BPD (OR 0.63, 95\% CI, 0.52-0.76; $\mathrm{p}<0.001$ ) [52]. Caffeine therapy was also associated with improved neurodevelopmental outcome in survivors at 18-21 months [53], but not at 5 years [54].

\section{The Present: Where Do We Stand Now?}

\section{State-of-the Art of Lung-Protective Respiratory}

Support in Preterm Infants

The major goals of any lung-protective strategy are (1) to avoid atelectrauma by promoting alveolar stability, (2) to limit tidal volume to prevent alveolar overdistension, and (3) to minimize oxygen toxicity by improving V/Q matching. Available data suggest that these goals can be successfully approached by different modes of respiratory support.

It is important to realize that even a short exposure to injurious mechanical ventilation and excessive oxygen exposure may induce lung injury [55]. In the delivery room, CPAP should be used early, and, during bag-mask ventilation, PEEP valves should be used to help establish and stabilize functional residual capacity. It is imperative that ventilation with large tidal volumes is avoided. To reduce the risk of oxygen toxicity, the provision of supplemental oxygen must be guided by pulse oximetry. When preterm infants with HMD fail a trial of CPAP, surfactant should be administered within the first hours of life.

During CMV, lung-protective ventilation can best be achieved by optimizing PEEP and by tidal volume targeting (i.e. 4-6 ml $/ \mathrm{kg}$ ) (fig. 3). Since compliance can change rapidly, particularly after surfactant administration to preterm infants with HMD, the required peak inflation pressures may have to be adjusted frequently. Alternatively, VTV should be used to reduce the risk of volutrau- 
Fig. 3. CMV. To avoid atelectrauma, PEEP is kept above the lower inflection point (LIP); peak inflation pressure (PIP) is chosen to generate a tidal volume (TV) of 4-6 $\mathrm{ml} / \mathrm{kg}$ to avoid volutrauma beyond the upper inflection point (UIP).

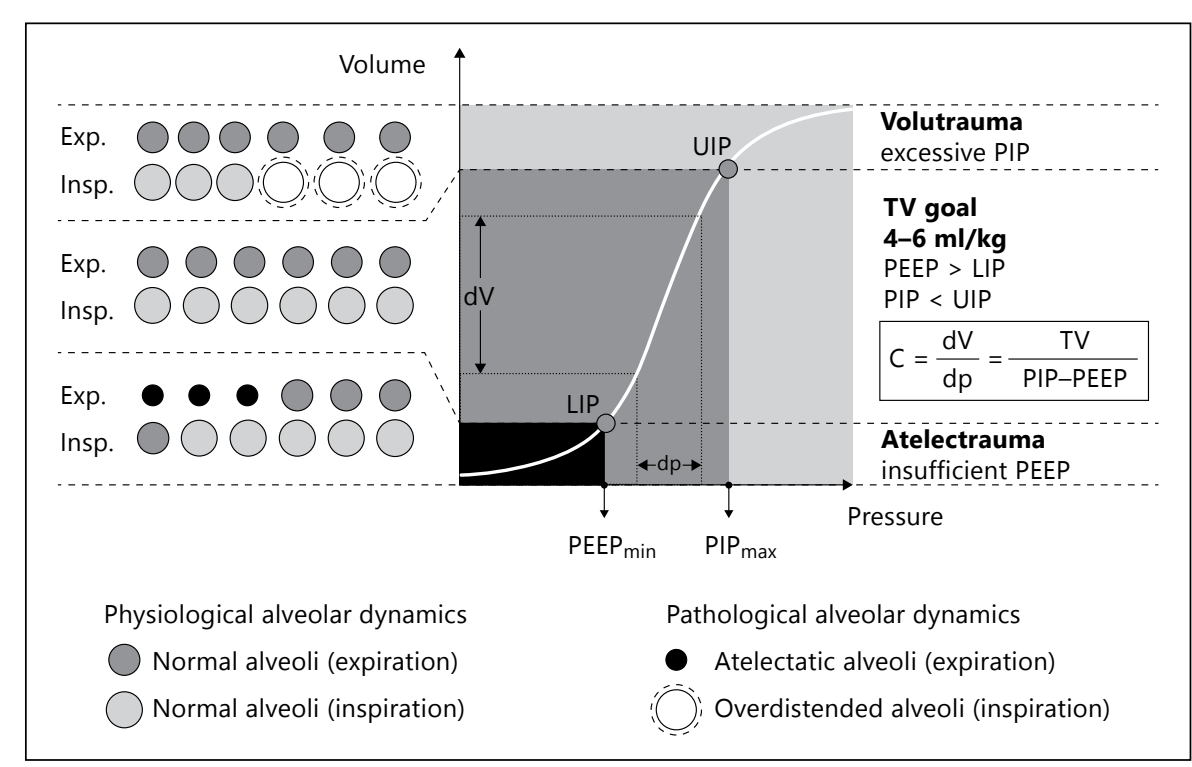

ma and hypocapnia [18]. Because the lungs of preterm infants with HMD have short time constants (i.e. the product of compliance and resistance), they can initially be ventilated with short inflation times $(0.25-0.4 \mathrm{~s})$. Once compliance improves, inflation times may need to be adjusted to allow inflation flow to return to zero before expiration starts.

During HFOV, an open lung concept must be used by choosing an appropriate level of mean airway pressure guided by improvements in oxygenation (i.e. the ability to reduce $\mathrm{FiO}_{2}$ to less than 0.25-0.30) [56] and demonstration of adequate lung expansion on conventional chest X-ray at regular intervals. Ventilation, on the other hand, depends on the pressure amplitude and the chosen frequency. With $\mathrm{HFOV}$, an increase in ventilator frequency will decrease $\mathrm{CO}_{2}$ elimination [57]. Since changes in compliance and resistance affect the corner frequency in opposite directions (i.e. the frequency below which the pressure cost of flow increases sharply), the choice of the optimal frequency during HVOF must be guided by the predominant pathology. In HMD, characterized by low compliance, higher frequencies can be used than, for example, in meconium aspiration syndrome where increased resistance predominates [58, 59].

The concept of permissive hypercapnia may further limit ventilator-induced lung injury regardless of whether CMV or HFOV is used [60]. In selected cases, iNO may improve oxygenation by improving ventilation-perfusion matching or decreasing pulmonary vascular resistance and right-to-left shunting across the ductus arterio- sus and/or the foramen ovale. In preterm infants, caffeine should be considered not only for the treatment of apnea of prematurity, but also to facilitate weaning and decrease the duration of mechanical ventilation.

\section{The Future: Any Leaps in Sight?}

\section{Defining Appropriate Oxygen Saturation Targets for \\ Preterm Infants}

In healthy term infants, with the transition from intrauterine to extrauterine life, arterial oxygen saturation increases substantially from about $65 \%$ to more than $95 \%$. The appropriate arterial oxygen saturation target in preterm infants is unknown, and exposure to high concentrations of oxygen is associated with increased risks of ROP and BPD [61]. Several recently published large prospective randomized controlled multicenter trials have addressed this issue [62-65]. Extremely preterm infants with a gestational age of less than 28 weeks were randomized either to a low (i.e. $85-89 \%$ ) or a high (i.e. 91-95\%) target oxygen saturation $\left(\mathrm{SaO}_{2}\right)$ group. The Surfactant, Positive Pressure, and Pulse Oximetry Randomized Trial (SUPPORT) Study Group reported a statistically significantly increased mortality rate among infants in the low $\mathrm{SaO}_{2}$ group compared to the infants in the high $\mathrm{SaO}_{2}$ group. On the other hand, rates of moderate-to-severe BPD and severe ROP were significantly lower in the low $\mathrm{SaO}_{2}$ group [62]. Researchers of the Benefits of Oxygen Saturation Targeting (BOOST II) found a similar trend in 
Table 2. Main findings of trials evaluating low (85-89\%) versus high (91-95\%) target oxygen saturations in extremely preterm infants [62-65]

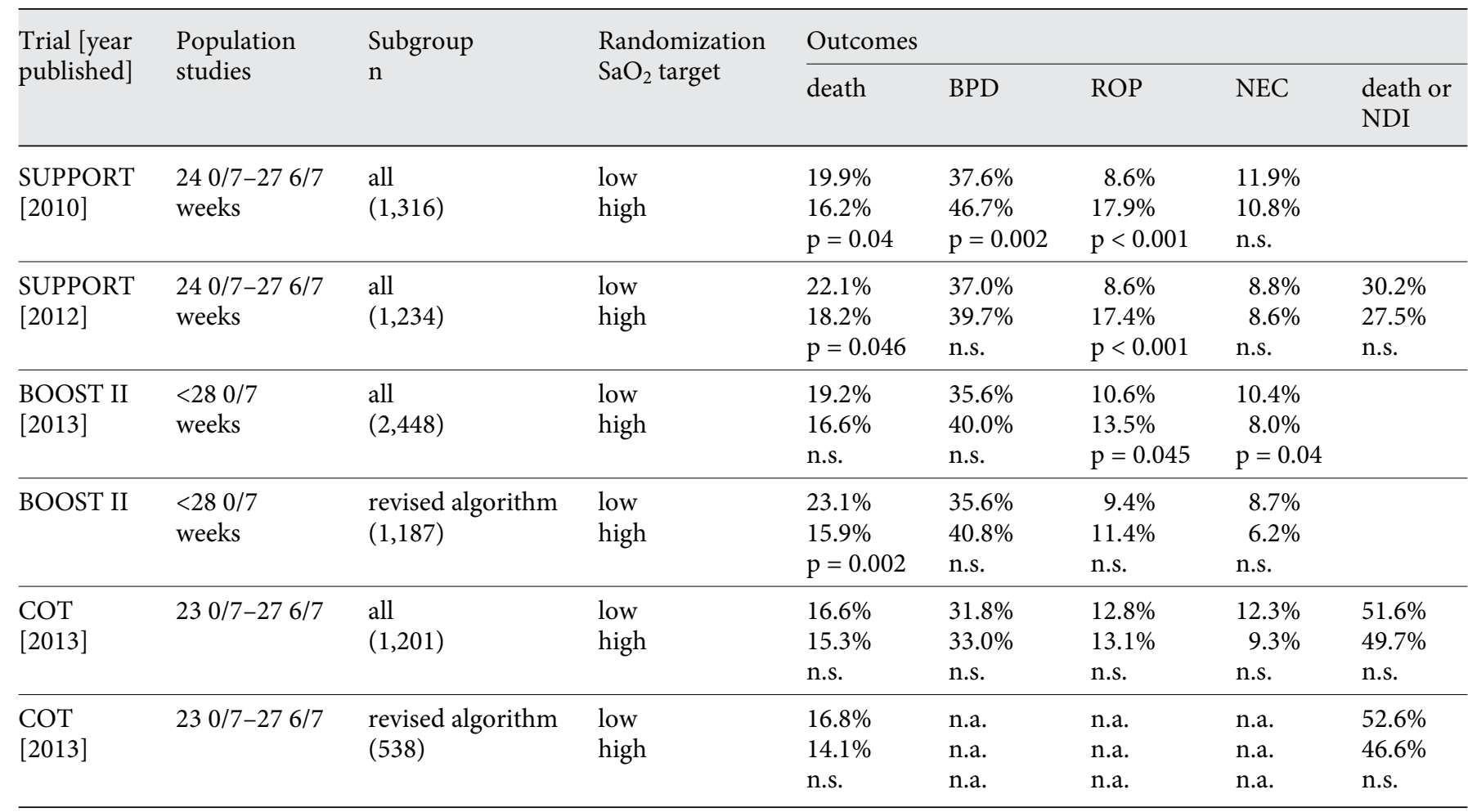

n.s. $=$ Not significant; n.a. $=$ not available.

mortality rates, which reached statistical significance among infants exposed to a revised oximeter-calibration algorithm [64]. In contrast, the Canadian Oxygen Trial (COT) found comparable rates of death among low and high $\mathrm{SaO}_{2}$ groups; these results did not change when only infants treated with a revised oximeter-calibration algorithm were analyzed [63]. Finally, both the SUPPORT trial and the COT trial, found no statistically different rates of death or neurodevelopmental impairment at 1822 months of corrected age $[63,65]$. The findings of these trials are summarized in table 2.

Interestingly, causes of death did not differ between the two $\mathrm{SaO}_{2}$ groups. In addition, the curves of mortality over time between the two $\mathrm{SaO}_{2}$ target groups appear to diverge only several weeks after birth. The authors of an editorial accompanying the publication of the COT trial have argued that there might be a possible benefit of targeting different $\mathrm{SaO}_{2}$ ranges at different postnatal ages [66]. Nevertheless, for the time being, it seems prudent to target $\mathrm{SaO}_{2}$ between 90 and $95 \%$ while avoiding extreme oxygenation levels (both hypoxia and hyperoxia) $[66,67]$.

\section{Synchronized Noninvasive Positive Pressure Ventilation}

Although experience with early CPAP to stabilize preterm infants and avoid invasive mechanical ventilation has greatly increased, success with this approach is limited $[39,40]$. Nasal intermittent positive pressure ventilation could potentially improve noninvasive respiratory support $[68,69]$. However, without synchronization, tidal volumes of spontaneously breathing preterm infants are only minimally augmented [70]. Currently used flow, pressure or abdominal motion triggers are unreliable. In recent years, neurally adjusted ventilatory assist, a technique that utilizes the electrical activity of the diaphragm to trigger mechanical breaths, has been shown to improve patient-ventilator interaction and synchrony even in the presence of large air leaks [71]. Whether nasal intermittent positive pressure ventilation with neurally adjusted ventilatory assist will make a difference in important clinical outcomes of preterm infants will have to be evaluated in randomized trials. 


\section{Large Potential for Low-Resource Countries}

Given the fact that progress made in the last decade has only resulted in minor improvements in mortality and morbidity rates of neonates with respiratory failure, it seems unlikely that further refinements of current technologies will produce giant leaps forward in high-resource countries. It appears that entirely new approaches would be required. In contrast, knowledge and technology transfer of basic respiratory support strategies (e.g. use of oxygen, simple systems to provide CPAP) could have an enormous impact on the prognosis of neonates with respiratory failure in low-resource countries [72, 73].

\section{Disclosure Statement}

We declare that we have no conflicts of interest.

\section{References}

1 Campbell K: Intensive oxygen therapy as a possible cause of retrolental fibroplasia: a clinical approach. Med J Aust 1951;2:48-50.

$\checkmark 2$ Avery ME: Recent increase in mortality from hyaline membrane disease. J Pediatr 1960;57: 553-559.

3 Avery ME, Mead J: Surface properties in relation to atelectasis and hyaline membrane disease. AMA J Dis Child 1959;97:517-523.

4 Peterson HG Jr, Pendleton M: Contrasting roentgenographic pulmonary patterns of the hyaline membrane and fetal aspiration syndromes. Am J Roentgenol Radium Ther Nucl Med 1955;74:800-817.

5 Fujiwara T, Maeta H, Chida S, Morita T, Watabe $\mathrm{Y}$, Abe T: Artificial surfactant therapy in hyaline-membrane disease. Lancet 1980;1: 55-59.

6 Northway WH Jr, Rosan RC, Porter DY: Pulmonary disease following respirator therapy of hyaline-membrane disease: bronchopulmonary dysplasia. N Engl J Med 1967;276: 357-368.

7 Gregory GA, Kitterman JA, Phibbs RH, Tooley WH, Hamilton WK: Treatment of the idiopathic respiratory-distress syndrome with continuous positive airway pressure. $\mathrm{N}$ Engl I Med 1971;284:1333-1340

$>8$ Liggins GC: Premature delivery of foetal lambs infused with glucocorticoids. J Endocrinol 1969;45:515-523.

-9 Liggins GC, Howie RN: A controlled trial of antepartum glucocorticoid treatment for prevention of the respiratory distress syndrome in premature infants. Pediatrics 1972;50:515525.

10 Roberts D, Dalziel S: Antenatal corticosteroids for accelerating fetal lung maturation for women at risk of preterm birth. Cochrane Database Syst Rev 2006;3:CD004454.

11 Soll RF, Blanco F: Early versus delayed neonatal administration of a synthetic surfactant the judgment of OSIRIS. The OSIRIS Collaborative Group (open study of infants at high risk of or with respiratory insufficiency) - the role of surfactant. Lancet 1992;340:13631369.

12 Soll RF, Blanco F: Natural surfactant extract versus synthetic surfactant for neonatal respi- ratory distress syndrome. Cochrane Database 24 Cools F, Askie LM, Offringa M, Asselin JM, Syst Rev 2001;2:CD000144.

13 Northway WH Jr: Bronchopulmonary dysplasia: twenty-five years later. Pediatrics 1992; 89:969-973.

14 Donn SM: Neonatal ventilators: how do they differ? J Perinatol 2009;29:S73-S78.

15 Greenough A, Dimitriou G, Prendergast M, Milner AD: Synchronized mechanical ventilation for respiratory support in newborn infants. Cochrane Database Syst Rev 2008; 1:CD000456.

16 Amato MB, Barbas CS, Medeiros DM, Magaldi RB, Schettino GP, Lorenzi-Filho G, et al: Effect of a protective-ventilation strategy on mortality in the acute respiratory distress syndrome. N Engl J Med 1998;338:347-354.

17 ARDS Network: Ventilation with lower tidal volumes as compared with traditional tidal volumes for acute lung injury and the acute respiratory distress syndrome. The Acute Respiratory Distress Syndrome Network. N Engl J Med 2000;342:1301-1308.

18 Wheeler KI, Klingenberg C, Morley CJ, Davis PG: Volume-targeted versus pressure-limited ventilation for preterm infants: a systematic review and meta-analysis. Neonatology 2011; 100:219-227.

19 Van Kaam A: Lung-protective ventilation in neonatology. Neonatology 2011;99:338-341.

20 Gerstmann DR, deLemos RA, Coalson JJ, Clark RH, Wiswell TE, Winter DC, et al: Influence of ventilatory technique on pulmonary baroinjury in baboons with hyaline membrane disease. Pediatr Pulmonol 1988;5:82-91.

21 Carney D, DiRocco J, Nieman G: Dynamic alveolar mechanics and ventilator-induced lung injury. Crit Care Med 2005;3:S122-S128.

22 The HIFI Study Group: High-frequency oscillatory ventilation compared with conventional mechanical ventilation in the treatment of respiratory failure in preterm infants. $\mathrm{N} \mathrm{Engl}$ J Med 1989;320:88-93.

23 Henderson-Smart DJ, De Paoli AG, Clark RH, Bhuta T: High frequency oscillatory ventilation versus conventional ventilation for infants with severe pulmonary dysfunction born at or near term. Cochrane Database Syst Rev 2009;3:CD002974. Calvert SA, Courtney SE, et al: Elective high-frequency oscillatory versus conventional ventilation in preterm infants: a systematic review and meta-analysis of individual patients' data. Lancet 2010;375:20822091.

25 Soll RF: Elective High-Frequency Oscillatory Ventilation versus Conventional Ventilation for Acute Pulmonary Dysfunction in Preterm Infants. Neonatology 2012;103:7-9.

26 Bryan AC, Froese AB: Reflections on the HIFI trial. Pediatrics 1991;87:565-567.

27 Stevenson DK, Wright LL, Lemons JA, Oh W, Korones SB, Papile LA, et al: Very low birth weight outcomes of the National Institute of Child Health and Human Development Neonatal Research Network, January 1993 through December 1994. Am J Obstet Gynecol 1998;179:1632-1639.

28 Husain AN, Siddiqui NH, Stocker JT: Pathology of arrested acinar development in postsurfactant bronchopulmonary dysplasia. Hum Pathol 1998;29:710-717.

29 Jobe AJ: The new BPD: an arrest of lung development. Pediatr Res 1999;46:641-643.

30 Avery ME, Tooley WH, Keller JB, Hurd SS, Bryan $\mathrm{MH}$, Cotton RB, et al: Is chronic lung disease in low birth weight infants preventable? A survey of eight centers. Pediatrics 1987;79:26-30

31 Dunn MS, Kaempf J, de Klerk A, de Klerk R, Reilly M, Howard D, et al: Randomized trial comparing 3 approaches to the initial respiratory management of preterm neonates. Pediatrics 2011;128:e1069-e1076.

32 Finer NN, Carlo WA, Walsh MC, Rich W, Gantz MG, Laptook AR, et al: Early CPAP versus surfactant in extremely preterm infants. N Engl J Med 2010;362:1970-1979.

33 Morley CJ, Davis PG, Doyle LW, Brion LP, Hascoet JM, Carlin JB: Nasal CPAP or intubation at birth for very preterm infants. N Engl J Med 2008;358:700-708.

34 Rojas-Reyes MX, Morley CJ, Soll R: Prophylactic versus selective use of surfactant in preventing morbidity and mortality in preterm infants. Cochrane Database Syst Rev 2012; 3:CD000510. 
-35 Verder H, Robertson B, Greisen G, Ebbesen F, Albertsen P, Lundstrom K, et al: Surfactant therapy and nasal continuous positive airway pressure for newborns with respiratory distress syndrome. Danish-Swedish Multicenter Study Group. N Engl J Med 1994;331:10511055.

- 36 Dani C, Bertini G, Pezzati M, Cecchi A, Caviglioli C, Rubaltelli FF: Early extubation and nasal continuous positive airway pressure after surfactant treatment for respiratory distress syndrome among preterm infants $<30$ weeks' gestation. Pediatrics 2004;113:e560-e563.

- 37 Reininger A, Khalak R, Kendig JW, Ryan RM, Stevens TP, Reubens L, et al: Surfactant administration by transient intubation in infants 29 to 35 weeks' gestation with respiratory distress syndrome decreases the likelihood of later mechanical ventilation: a randomized controlled trial. J Perinatol 2005; 25:703-708.

- 38 Rojas MA, Lozano JM, Rojas MX, Laughon $\mathrm{M}$, Bose CL, Rondon MA, et al: Very early surfactant without mandatory ventilation in premature infants treated with early continuous positive airway pressure: a randomized, controlled trial. Pediatrics 2009;123:137-142.

-39 Tooley J, Dyke M: Randomized study of nasal continuous positive airway pressure in the preterm infant with respiratory distress syndrome. Acta Paediatr 2003;92:1170-1174.

-40 Pfister RH, Soll RF: Initial respiratory support of preterm infants: the role of CPAP, the INSURE method, and noninvasive ventilation. Clin Perinatol 2012;39:459-481.

-41 Sandri F, Plavka R, Ancora G, Simeoni U, Stranak Z, Martinelli S, et al: Prophylactic or early selective surfactant combined with nCPAP in very preterm infants. Pediatrics 2010;125:e1402-e1409.

-42 Kattwinkel J, Robinson M, Bloom BT, Delmore P, Ferguson JE: Technique for intrapartum administration of surfactant without requirement for an endotracheal tube. J Perinatol 2004;24:360-365.

-43 Trevisanuto D, Grazzina N, Ferrarese P, Micaglio M, Verghese C, Zanardo V: Laryngeal mask airway used as a delivery conduit for the administration of surfactant to preterm infants with respiratory distress syndrome. Biol Neonate 2005;87:217-220.

-44 Dargaville PA, Aiyappan A, Cornelius A, Williams C, De Paoli AG: Preliminary evaluation of a new technique of minimally invasive surfactant therapy. Arch Dis Child Fetal Neonatal Ed 2011;96:F243-F248.

45 Kribs A, Pillekamp F, Hunseler C, Vierzig A, Roth B: Early administration of surfactant in spontaneous breathing with nCPAP: feasibility and outcome in extremely premature infants (postmenstrual age $</=27$ weeks). Paediatr Anaesth 2007;17:364-369.
46 Gopel W, Kribs A, Ziegler A, Laux R, Hoehn $\mathrm{T}$, Wieg C, et al: Avoidance of mechanical ventilation by surfactant treatment of spontaneously breathing preterm infants (AMV): an open-label, randomised, controlled trial. Lancet 2011;378:1627-1634.

-47 Kanmaz HG, Erdeve O, Canpolat FE, Mutlu B, Dilmen U: Surfactant administration via thin catheter during spontaneous breathing: randomized controlled trial. Pediatrics 2013; 131:e502-e509.

48 Finer NN, Barrington KJ: Nitric oxide for respiratory failure in infants born at or near term. Cochrane Database Syst Rev 2006; 4:CD000399.

49 Sosenko IR, Bancalari E: NO for preterm infants at risk of bronchopulmonary dysplasia. Lancet 2010;376:308-310.

50 Barrington KJ, Finer N: Inhaled nitric oxide for respiratory failure in preterm infants. Cochrane Database Syst Rev 2010;12:CD000509.

51 Donohue PK, Gilmore MM, Cristofalo E, Wilson RF, Weiner JZ, Lau BD, et al: Inhaled nitric oxide in preterm infants: a systematic review. Pediatrics 2011;127:e414-e422.

52 Schmidt B, Roberts RS, Davis P, Doyle LW, Barrington KJ, Ohlsson A, et al: Caffeine therapy for apnea of prematurity. N Engl J Med 2006;354:2112-2121.

53 Schmidt B, Roberts RS, Davis P, Doyle LW, Barrington KJ, Ohlsson A, et al: Long-term effects of caffeine therapy for apnea of prematurity. N Engl J Med 2007;357:1893-1902.

54 Schmidt B, Anderson PJ, Doyle LW, Dewey D, Grunau RE, Asztalos EV, et al: Survival without disability to age 5 years after neonatal caffeine therapy for apnea of prematurity. JAMA 2012;307:275-282.

55 Bjorklund LJ, Ingimarsson J, Curstedt T, John J, Robertson B, Werner O, et al: Manual ventilation with a few large breaths at birth compromises the therapeutic effect of subsequent surfactant replacement in immature lambs. Pediatr Res 1997;42:348-355.

56 De Jaegere A, van Veenendaal MB, Michiels $A$, van Kaam AH: Lung recruitment using oxygenation during open lung high-frequency ventilation in preterm infants. Am J Respir Crit Care Med 2006;174:639-645.

57 Sturtz WJ, Touch SM, Locke RG, Greenspan JS, Shaffer TH: Assessment of neonatal ventilation during high-frequency oscillatory ventilation. Pediatr Crit Care Med 2008;9:101104.

58 Pillow JJ: High-frequency oscillatory ventilation: mechanisms of gas exchange and lung mechanics. Crit Care Med 2005;33:S135S141.

59 Venegas JG, Fredberg JJ: Understanding the pressure cost of ventilation: why does highfrequency ventilation work? Crit Care Med 1994;22:S49-S57.
60 Ryu J, Haddad G, Carlo WA: Clinical effectiveness and safety of permissive hypercapnia. Clin Perinatol 2012;39:603-612.

61 Saugstad OD, Aune D: In search of the optimal oxygen saturation for extremely low birth weight infants: a systematic review and metaanalysis. Neonatology 2011;100:1-8.

62 Carlo WA, Finer NN, Walsh MC, Rich W, Gantz MG, Laptook AR, et al: Target ranges of oxygen saturation in extremely preterm infants. N Engl J Med 2010;362:1959-1969.

63 Schmidt B, Whyte RK, Asztalos EV, Moddemann D, Poets C, Rabi Y, et al: Effects of targeting higher vs lower arterial oxygen saturations on death or disability in extremely preterm infants: a randomized clinical trial. JAMA 2013;309:2111-2120.

-64 Stenson BJ, Tarnow-Mordi WO, Darlow BA, Simes J, Juszczak E, Askie L, et al: Oxygen saturation and outcomes in preterm infants. $\mathrm{N}$ Engl J Med 2013;368:2094-2104.

65 Vaucher YE, Peralta-Carcelen M, Finer NN, Carlo WA, Gantz MG, Walsh MC, et al: Neurodevelopmental outcomes in the early CPAP and pulse oximetry trial. N Engl J Med 2012; 367:2495-2504.

66 Bancalari E, Claure N: Oxygenation targets and outcomes in premature infants. JAMA 2013;309:2161-2162.

67 Polin RA, Bateman D: Oxygen-saturation targets in preterm infants. N Engl J Med 2013; 368:2141-2142.

68 Bhandari V, Gavino RG, Nedrelow JH, Pallela P, Salvador A, Ehrenkranz RA, et al: A randomized controlled trial of synchronized nasal intermittent positive pressure ventilation in RDS. J Perinatol 2007;27:697-703.

-69 Kugelman A, Feferkorn I, Riskin A, Chistyakov I, Kaufman B, Bader D: Nasal intermittent mandatory ventilation versus nasal continuous positive airway pressure for respiratory distress syndrome: a randomized, controlled, prospective study. J Pediatr 2007;150:521526.

70 Owen LS, Morley CJ, Dawson JA, Davis PG: Effects of non-synchronised nasal intermittent positive pressure ventilation on spontaneous breathing in preterm infants. Arch Dis Child Fetal Neonatal Ed 2011;96:F422-F428.

71 Beck J, Reilly M, Grasselli G, Mirabella L, Slutsky AS, Dunn MS, et al: Patient-ventilator interaction during neurally adjusted ventilatory assist in low birth weight infants. Pediatr Res 2009;65:663-668.

72 Kamath BD, Macguire ER, McClure EM, Goldenberg RL, Jobe AH: Neonatal mortality from respiratory distress syndrome: lessons for low-resource countries. Pediatrics 2011; 127:1139-1146.

73 Berger TM. Neonatal respiratory care: not how, but where and when. Lancet Resp Med 2013;1:280-282. 